\title{
Los exilios de Herta Müller
}

\author{
Luis A. Acosta GómeZ \\ Departamento de Filología Alemana \\ Universidad Complutense de Madrid \\ 1scst@filol.ucm.es
}

\section{RESUMEN}

Sin duda Herta Müller se ha convertido en una escritora ampliamente reconocida a partir de la concesión del premio Nobel en 2009. Este artículo pretende una aproximación crítica al significado de su obra literaria. Para ello, se consideran en primer lugar las reacciones de la prensa alemana y rumana sobre la concesión del premio. A continuación se analizan su primer texto publicado en Rumanía, y la evolución y confirmación de una manera peculiar de hacer literatura ya durante el exilio alemán, para centrar el estudio en la obra culminante y más significativa de todas las escritas hasta el momento del galardón. Desde una perspecti va sociológica, el artículo se adentra en la evolución de su quehacer literario considerando los dos exilios que ha vivido, en los que la memoria histórica se convierte en punto de orientación de su actividad.

Palabras clave: literatura de Herta Müller, Premio Nobel y reacciones de la prensa, evolución de la escritura, la literatura como memoria, la experiencia del exilio y la pertenencia a un país.

\section{The exiles of Herta Müller}

\begin{abstract}
Certainly Herta Müller became a lar gely recognized writer ever since the conferment of de Nobel Price in the year 2009. This article deals with a critic approach to the signification of her texts. There are first of all observed the press German and Romanian reactions about the conferment of the price. Thereafter is analyzed her first in Romania publicized text Niederungen and the latter evolution and confirmation of a peculiar writing already in the German exil and at the last the most important and characteristic of all her production Atemschaukel. Under a sociological point of view this contribution it deals the evolution of her literary texts by considering both exiles she has experienced where the historic memory becomes an essential guideline.
\end{abstract}

Key words: Herta Müller 's literature, Nobel Price and press' reaction, evolution of her texts, writing as memory, the experience of the exile and the fatherland belonging. 


\section{REACCIONES DE LA PRENSA}

E1 8 de octubre del año 2009 la Academia Sueca anunció la concesión del premio Nobel de literatura a la escritora Herta Müller. Era la segunda escritora en lengua alemana, tras Elfriede Jelinek, a quien se le concedía tal premio en los últimos seis años. Las reacciones en los distintos círculos sociales no se hicieron esperar De la propia Academia Sueca llegó la primera valoración referida al significado tanto literario como social de la obra de la recién galardonada. Así Englund, el secretario de la academia, al tiempo que daba la noticia por radio, hizo una caracterización fundamental, como la de una escritora que "mediante la concentración de su poesía y la objetividad de la prosa" había construido "mundos propios de los despatriados [...]. Escribe con perfecta honradez y sin tenerse en consideración a sí misma, [...] tiene historias que contar" y dispone "de los resortes lingüísticos para ello" ${ }^{1}$.

La Iglesia católica alemana se manifestó en boca de su arzobispo Robert Zollitsch admirando la obra de Herta Müller por la fuerza lingüística y la intensidad de sus pensamientos. Dijo sentirse a la expectativa de su nueva novela Balanceo del aliento $^{2}$, cuya temática le recuerda su propio pasado doloroso. El obispo W. Huber, por su parte, se expresó diciendo que mediante narraciones genuinas ha logrado acercar al lector las experiencias vividas en un régimen de injusticia ( Katholische Nachrichten 2009).

Según información del diario Frankfurter Rundschschau, el Presidente Federal H. Köller se manifestó en el sentido de que "Müller ha lanzado un grito contra el olvido y de este modo recordado el alto valor de la libertad. Por ello es para mí una idea muy feliz que un escritor tal haya conseguido el premio, precisamente en este año en que recordamos el final hace veinte de las dictaduras de Europa Oriental. Müller siempre ha descrito al detalle y con emoción el efecto que un sistema de injusticias produce en las almas y corazones de los seres humanos, la opresión y el despotismo que caracterizan la vida de todos los días de una sociedad y del indivi duo" (Frankfurter Rundschau. Feuilleton 2009a). El alcalde de Berlín K. Wowereit congratuló a la autora, que en la actualidad vive en la capital alemana, con las pala bras: "Felicito a nuestra conciudadana Herta Müller en nombre de todos los berlineses por su singular éxito que con seguridad le ha sorprendido también a ella". A continuación expresó el interés político evidente que encerraba su intención: "A todos nos enorgullece que una autora a quien se le concedió en 2005 el premio de literatura de la ciudad de Berlín consiga en esta ocasión el máximo honor en el mundo de la literatura. Al enfrentarse en sus obras al pasado comunista de Rumanía y al destino de la minoría alemana que encontró allí su tierra, le pareció ser Berlín, como ciudad en su momento dividida, el lugar en el que se daban las condiciones

1 Emisión radiofónica recogida en toda la prensa alemana relevante. La traducción de todos los textos en alemán es del autor de este artículo.

2 Mientras tanto, se ha traducido al español el título sirviéndose de la primera frase de la obra Todo lo que tengo lo llevo conmigo, lo que en mi opinión es desacertado. Esta novela ha aparecido en el año 2010 en la editorial Siruela. 
adecuadas para su trabajo" (Frankfurter Rundschau. Feuilleton 2009b). "Me alegro sobremanera de que el Comité haya otogado el premio a Herta Müller Herta Müller es una de las escritoras que se ha más que merecido esta distinción. Escribe una lite ratura excelente alimentada por una experiencia que habla de dictadura, opresión y miedos, pero también de coraje increíble [...]. Naturalmente nos alegramos de que Herta Müller haya encontrado en Alemania una tierra [...]", palabras de la canciller federal Angela Merkel (Regierungonline 2009).

Günter Grass se manifestó satisfecho del honor a Herta Müller y además expresó su parecer en el sentido de que se trata de una muy buena autora de novela, a pesar de que su favorito para este año había sido el escritor israelí Amos Oz (Spiegel online 2009). Su opinión sobre la autora ha de entenderse no obstante positiva con restricciones. El pope, por así decirlo, de la crítica literaria alemana Marcel Reich-Ranicki, preguntado por la premio Nobel, rechazó hacer comentario alguno: "No quiero hablar de Herta Müller . Adiós", dijo en una conversación telefónica (Tagesschau 2009). Y preguntado sobre su decepción por el hecho de no haber sido considerado el escritor norteamericano Philip Roth dijo: "Yá son muchos años en los que no recibe el premio.Además he contado con que esta vez lo recibiría una mujer" (Frankfurter Rundschau 2009). El escritor Thomas Brussig dijo sobre la concesión: "En cualquier caso se ha acertado con la escritora" ( Der Tagesspiegel 2009).

Mientras en Alemania las manifestaciones fueron casi unánimes sobre la concesión, no fue así en Rumanía. Para el escritor y crítico del régimen de Ceausescu Paul Goma (tuvo que abandonar el país en 1977), "el premio Nobel no tiene nada que ver con Rumanía. La galardonada nunca ha dicho que sea una escritora rumana, sino una escritora del Banat. Aparte de eso no ha sentido en su persona el exilio, Alemania la ha recogido". Goma se manifestó irritado por que Müller fuera considerada de procedencia rumana (Welt online 2009). Para el reconocido periodista rumano Cristian Tudor Popescu, Müller ha logrado el premio Nobel sobre todo por su trasfondo cultural alemán y el compromiso político, de manera que de haberse quedado en Rumanía no lo habría conseguido. Popescu se manifestó en el sentido de que ante todo Nicolae Ceausescu fue decisivo para el premio a la escritora: "He visto la conferencia de prensa: No ha hecho más que hablar de dictadura y no de literatura. Igual que si fuera Nelson Mandela. Tal vez habría sido más adecuado el premio Nobel de la Paz" (Welt online 2009). De manera totalmente distinta se expresó el relevante crítico literario del país Nicolae Manolescu, quien identificó en Herta Müller una representante de la cultura rumana: "Es un momento muy especial y me alegro por Herta y por Rumanía de que le hayan concedido este premio inesperado. Sobre todo si se analiza la lista de candidatos y se descubre a autores como Amos Oz o Philip Roth se sabe entonces qué es lo que realmente significa. Ha elegido temas que son importantes para ambos países y para Europa" (Welt online 2009). El filósofo Andrei Plesu piensa que Herta Müller es a decir verdad una escritora alemana, si bien su procedencia es rumana y sus obras contienen una parte de la historia rumana y alemana" (Welt online 2009). Con actitud neutral, Rea Cristina Modreanu comentó que Müller puede convertirse en una señal, un símbolo de la sociedad rumana. No es momento ahora de despertar el or gullo nacional, sino la conciencia de un país que todavía no ha recapacitado sobre su pasado comunista. (Welt online 2009). Para 
Horia Roman Patapievici, presidente del Instituto Nacional de Cultura Rumano, el premio no es una cuestión de alemanidad o rumanidad. Es una prueba de que "[...] los traumas del comunismo, veinte años después del final del totalitarismo, están integrados en la memoria colectiva de Europa" (Welt online 2009). Mircea Cartarescu, uno de los más reconocidos escritores rumanos, nacido en 1956, el mismo año que Herta Müller, llegó a escribir que habla rumano al igual que él mismo. Está impregnada de la lengua, literatura y cultura rumanas. Todo lo que ha escrito se desarrolla en Rumanía, un país al que ama y odia, un país que aunque la hiera es parte de su memoria viva. Le pertenece al menos tanto como le pertenece Alemania. La dictadura, tan barroca como criminal, ha hecho de ella lo que es en la actualidad (Cartarescu 2009). Y por fin la última manifestación de las muchas a las que todavía podría aludirse: Beatrice Ungar , redactora jefe del Hermannstädter Zeitung, semanario del distrito rumano de Hermannstadt de Sibiu, declaró que Müller para ella es una escritora alemana proceda de donde proceda, una escritora a la que ve como alemana en Rumanía. Se pregunta uno qué parte de su persona es rumana y cuál alemana. La denominación más adecuada sería 'autora berlinesa'. En su pasaporte reza 'nacionalidad rumana'. Otra cuestión en cambio es la identidad ( Frankfurter Allgemeine Zeitung 2009).

Todas estas manifestaciones están muy bien. Sólo que no dicen mucho acerca de la obra de la autora, y si dicen algo lo dicen sólo en sentido político o diplomático por no decir nacional. Sus textos, sin embar go, permiten muchas posibilidades de análisis de ninguna manera expresadas en lo dicho. Con todo, de ello se intuye lo que aquí interesa, es decir, cómo Herta Müller es, en realidad, una escritora del exilio, un exilio que ofrece varias manifestaciones: un exilio familiar y social, por lo tanto, un exilio interior y al mismo tiempo un exilio exterior .

\section{COMIENZOS CON NIEDERUNGEN (EN TIERRAS BAJAS) ${ }^{3}$}

Con Niederungen se presenta un mundo peculiar; un mundo, podría decirse, pequeño y aislado en sí mismo que, en principio, no es otro que el de una pequeña localidad del Banat rumano llamada Nitzkidorf situada al suroeste del país. Podría, de entrada, dar la impresión de que se trata de una presentación costumbrista de ese mundo, de una obra que no va más allá de una serie de narraciones yuxtapuestas.

Pero no es así. La capacidad del ojo observador pasa revista a todo lo que ocu rre en ese lugar cerrado en el que parece reinar entre los moradores un odio y un miedo infernales. La observación va dirigida a todo lo que en él tiene vida, incluidos los gestos y las andanzas de los moradores. En ese universo existe una separa ción entre el mundo de los adultos y el de los niños. Los pequeños y, por extensión, los demás componentes también están controlados por el ambiente cerrado de la familia, de manera que al control férreo practicado por la pequeña sociedad de un pequeño pueblo se añade el control al menos tan férreo de la familia, en la que el

3 La traducción ha sido publicada por la editorial Siruela en 1990. 
dominio está ejercido no sólo por los padres sino también por los abuelos. La auto ra presenta las consecuencias que todo ello trae consigo.

Los padres ejercen un tipo de autoridad que no es otra cosa que el autoritarismo rígido propio de una sociedad patriarcal cerrada. En ella además, a la cabeza que representa el padre, la madre no sirve de contrapartida como podría ocurrir en otros grupos sociales más modernos. La madre colabora en aumentar la rigidez mediante una actuación típica tradicional en la que no faltan incluso las palizas y los consiguientes sufrimientos. De ese modo se continúa una tradición histórica de la que a la autora no le resulta posible desprenderse. A ello habría que añadir el control ejercido también por los abuelos, que en muchas ocasiones se convierte en un control activo y colaborador del que ejercen los padres.

Pero saliendo del mundo estrictamente familiar , la escritora ofrece un cuadro logrado de un ambiente social del que son protagonistas unos vecinos que, al igual que los miembros de la familia, son personas destruidas y desgraciadas que no se encuentran en situación de ofrecer ningún tipo de valor positivo. No es más lo que pueden ofrecer el cura, el médico o el veterinario. De ello podrían ser una muestra las costumbres y rituales de las fiestas y celebraciones locales, en las que la Iglesia constituye una buena parte. Así los entierros, que son una expresión fiel de unas costumbres ancestrales, la creencia en las brujas, los chismorreos, etc. Dentro de todo ello, llama especialmente la atención la manía por la limpieza.

A medida que se leen las sesenta narraciones de que está construida la obra se observa la creación literaria paulatina de un nexo de unión que, al fin y al cabo, determina el conjunto de un todo estructurado a la perfección. Es la creación de un mundo ficcional que va más allá del exclusivamente vivido por la autora real. En ese mundo ficticio tiene lugar una repetición permanente de lo mismo, todo está or ganizado de acuerdo con unos resortes y unas pautas de comportamiento inmutables. Además es un mundo que resulta agobiante y angustioso, más llamativo aún por tratarse de una realidad a la que todos están acostumbrados. La fuerza de la costumbre hace que nadie se sienta indignado y que nadie emprenda nada para salir de ella, porque nadie se detiene siquiera a pensar que lo que ocurre sea cuestionable. Si hay alguien que se siente indignado es la niña protagonista, observadora omnisciente de la realidad, alguien que tiene la experiencia de una familia y un grupo social de peculiaridades arcaicas, en los que la vida se orienta según normas restrictivas y pre hibitivas, en los que a las chicas no les está permitido llorar, los niños tienen prohibido hablar durante la comida y la educación se identifica prácticamente con el castigo corporal. En una sociedad familiar de esta naturaleza no existen ni el afecto ni el cariño. El efecto que todo ello produce en la pequeña es el de sentirse en una situación de desesperanza en un mundo en el que el tejido social está destruido y hundido. Se entiende que ella no sepa expresarlo.

La reacción consecuente es la de escapar de todo dentro de las posibilidades que tiene a su alcance. Se va a la vía del ferrocarril, se interna en el bosque o se acerca al río, los únicos lugares donde siente que puede encontrarse consigo misma. El mundo de los pensamientos puede proporcionarle una salida a su situación, le permite escapar además al mundo de los sueños. La autora se sirve de ellos como recur so que refleja la fantasía literaria como componente de la construcción de la obra en 
que desaparece la frontera entre los mundos de la realidad y de la fantasía. Ello le ayuda a crear ese mundo de ficción literaria. El lector puede pensar que se trata de una presentación literarizada de las experiencias vividas por la autora real en su niñez y adolescencia en Nitzkidorf. Pero la perspectiva narrativa no es una perspectiva autorial, sino una cuyo resultado es una simbolización extraída de las experiencias personales que se sintetizan en la narración y se convierten en un discurso lite rario entrecortado por las distintas partes que constituyen la obra. El lector además ha de desempeñar un papel muy importante en la construcción de la obra. A partir del material escrito, encuentra lagunas que tiene que cubrir. Una de ellas es la crítica y el tipo de crítica encerrada que puede descubrir a lo lar go del texto. Porque no puede afirmarse que el texto sea una crítica limitada sólo a una sociedad rural y patriarcal tal y como puede encontrarse en cualquier parte del mundo. La pobreza presentada y el esfuerzo diario que produce un trabajo continuado al igual que la sociedad inmovilista no son necesariamente sólo producto de ese tipo de sociedades.

Está fuera de toda duda que con su primera obra la autora ha ido más allá del cos tumbrismo. Herta Müller no se manifiesta ni en este ni en trabajos posteriores como una escritora disidente, tampoco es esa su intención. Puede decirse que la orientación literaria que se manifiesta ya inicialmente prueba la intertextualidad, ya no sólo dentro de la literatura escrita en lengua alemana sino también en la literatura mundial. "[...] las frases breves en verdad hacen vislumbrar la lengua de los niños, pero lo hacen a la manera de la literatura; piénsese por ejemplo en Portrait of the Artist as a Young Man de Joyce, obra que comienza con breves frasecitas a fin de deletrear la percepción de los niños de corta edad. El tema de la mirada cándida del niño forma incluso parte del discurso de la modernidad artística" (Köhnen 2002: 20).

La obra es una crítica, unas veces más velada y otras menos, al sistema socialista que controla el tejido social desde unos principios igualmente inamovibles, como los de una or ganización rural. Va dirigida contra esa forma social de or ganización que aboca, al mismo tiempo que al inmovilismo, en algunos casos incluso a la pobreza. No es por ello de extrañar que la autoridad política intervenga la obra en su versión oficial siguiendo una forma de actuación generalizada en todos los regímenes autoritarios, en la que no faltan los argumentos justificativos de su actuación. El servicio secreto parece haber ido más allá del papel asignado al lector de literatura cuando, por razones que no ha podido encontrar en la obra, explica en un informe que "Herta Müller forma parte de un grupo de jóvenes escritores conocidos por su oposición al Estado", para terminar diciendo que "Critica una y otra vez, critica de una manera tan destructiva que uno se pregunta qué sentido tienen en realidad los textos que escribe" (Köhnen 2002: 20). El objetivo de la policía secreta no era otro que el de apartar a la escritora de una actividad como autora que no responde a las expectativas del sistema político oficial. En cualquier caso, aunque la crítica del texto al sistema no sea directa, el lector puede muy bien entender que se trata de un símbolo velado de esa realidad representado por la dictadura que pretende organizar la vida de todos los días, una dictadura con connotaciones similares a la dictadura familiar pero, a fin de cuentas, con efectos opresivos. El autor real ha pretendido un juego literario creador con la mezcla de dos tipos de dictadura igualmente determinantes en la vida de los seres humanos de una pequeña localidad. Y no resulta sor- 
prendente, pues habiendo nacido dentro de una familia acomodada de la minoría alemana suaba del Banat, Herta Müller tuvo que vivir en la propia persona el cambio que supuso la expropiación a que su familia fue sometida bajo el régimen comunista. A ello habría que añadir el recuerdo de la historia de la deportación de su madre a la Unión Soviética y del trabajo forzado consiguiente de años de duración a partir de 1945.

Además, la situación en que la autora misma se encuentra en los años anteriores y en el momento de escribir la obra no deja de tener importancia. En ellos la relación con las autoridades no fue precisamente positiva, ya que en el año 1976, como consecuencia de negarse a colaborar con laSecuritate, fue despedida del trabajo que desempeñaba como traductora en una fábrica. Tampoco ha podido eliminar de su memoria las consecuencias que ello trajo consigo: tener que trabajar para ganarse la vida ocupándose ocasionalmente en labores en escuelas e impartiendo horas privadas de alemán. Por otra parte, su actividad como única mujer en un grupo de escri tores jóvenes controlados por la policía trajo también sus consecuencias. No fue por casualidad que la publicación de Niederungen en Rumanía fuera con una fuerte censura oficial del texto original y después de haber sido retenida durante cuatro años. Tampoco extraña, pero por razones sur gidas no de la crítica política, que suabos de la zona considerasen la obra como algo que ensuciaba la propia casa (Auf fermann et al. 2009: 378-382).

Con frecuencia los libros sobre malos tiempos son leídos como testimonios. También en mis libros se trata necesariamente de malos tiempos, de una vida amputada en la dictadura, de una vida diaria externamente humillada, pero internamente soberana de una minoría alemana y de su posterior desaparición emigrando aAlemania. Por ello, para muchos mis libros son testimonios. Pero cuando escribo no me siento testigo. He aprendido a escribir desde el silencio. (Müller 2002: 6)

La obra es además un trabajo de observación literaria sobre una pequeña minoría alemana suaba en Rumanía, cuya vida diaria se ha convertido en una especie de dictadura y que es la realidad en que ha vivido la narradora. Un grupo social for mado en su mayor parte de emigrantes llegados a lo lar go del tiempo, que han traído como no podía ser de otra manera sus costumbres y que las han mantenido en la nueva patria chica. Unas costumbres, a fin de cuentas, que se identifican con las típicas que forman elementos constitutivos de lo que -con prejuicio o no- se entiende como la alemanidad 'clásica': la diligencia, la limpieza, el orden, la obediencia, la religiosidad, y que la autora no duda de ninguna manera en criticar Pero como se ha dicho más arriba, la opresión del ambiente se especifica en la metáfora de cuyo significado la niña no es consciente mientras que es niña. El yo narrador sabe que de ello se ha dado cuenta no precisamente en el campo sino posteriormente en la ciudad. Allí se dará cuenta además de la opresión de la otra dictadura. Es la metáfora de las ranas, de manera especial de la rana alemana, tal y como se menciona al final del texto:

Las ranas croaban desde los pulmones negros de mi padre muerto, de la tráquea negra de mi abuelo estertóreo, de las venas calcificadas de mi abuela. Las ranas 
croaban desde todos los vivos y muertos del pueblo. Todos ellos habían traído una rana con la emigración. Desde que existen celebran ser alemanes y no hablan de sus ranas y creen que aquello de lo que se niegan a hablar tampoco existe. Luego se durmió. Me caí dentro de un enorme tintero. En la Selva Negra tenía que ser así de oscuro. Fuera croaban sus ranas alemanas. También mi madre había traído de Rusia una rana. Y oigo la rana alemana de mi madre hasta después del sueño. (Müller 1984: 94)

Este es el mundo del que la protagonista desea escapar y que todavía no tiene nombre para ella. Por ello no extraña que además sienta miedo. Son para el yo narrador la conjunción mencionada antes de dos niveles de la realidad. Lo que la niña observadora capta y lo que no puede entender. La rana alemana no es otra que fundamentalmente el exceso de normas, como de alguna manera hace ver en las narra ciones "Die Grabrede" ("El panegírico"), "Das schwäbische Bad" ("El baño suabo"), "Der deutsche Scheitel und der deutsche Schnurrbart" ("La raya del pelo alemana y el bigote alemán"), que contrasta con el parecer ser y no ser del grupo social.

Mientras que en las dos últimas narraciones se evidencia la crítica a la minoría, en la primera el juego literario con la realidad no sobrepasa las fronteras de la autenticidad. Toda una serie de generaciones de emigrados suabos han conservado, generación tras generación, la costumbre, según un ritual, de bañarse los domingos en una misma bañera con la misma agua persona a persona: madre, padre, abuela y abuelo para terminar con la niña de dos años. La minoría de la zona actúa con una uniformidad en la que el individuo ha perdido la personalidad y lo único que cuenta es la colectividad a que cada uno se debe. Terminado el baño y todos aseados esperan sentados ante el televisor a que llegue la película de la tarde. Interesante es observar cómo el desarrollo repetitivo del ritual del baño se refleja en un desarrollo similar en la utilización de la lengua literaria mediante repeticiones, variaciones $\mathrm{y}$, a la postre, paralelismos y comparaciones.

En "Der deutsche Scheitel und der deutsche Schnurrbart", en que se describe la eterna repetición de lo mismo -no en el sentido nietzscheano naturalmente-, el ambiente tenebroso y enmarañado de un lugar en el que nunca ocurre nada más que un estado situado entre la vigilia y el sueño y donde el individuo tampoco tiene nombre dentro de la colectividad: "En el pueblo es crepúsculo a todas horas [...]. No hay ni un crepúsculo matutino ni uno vespertino. El crepúsculo está en las caras de la gente" (Müller 1984: 129). En la peluquería se sientan los hombres a la espera de su turno en completo silencio y de la pregunta de siempre del peluquero "¿Con raya alemana?". Es una pregunta que responde a la exigencia grotesca colectiva que impide la ruptura con la normalidad. El ritual de la eterna repetición del mismo corte y el mismo bigote alemanes se repite triunfador. La única posibilidad y peligro consiguiente de la ruptura de la norma con la llegada al pueblo de un individuo se conjuga con su despedida.

Sin duda mucho más mordiente es la narración "Die Grabrede" en que, con el juego de la conjunción de realidad y sueño, pasado y presente, la obra consigue la manifestación más plausible de lo que literariamente es. Por la mente del yo narrador pasan recuerdos del nacionalsocialismo y de la dictadura rumana mientras 
observa el cadáver de su padre. En él recuerda el saludo hitleriano, las runas SS, el trabajo forzado en Rusia y al conductor de camión a la vuelta del cautiverio; en defi nitiva, alguien de un pasado fanático como nazi y criminal de guerra acomodado en la nueva dictadura socialista. El juego literario de la generalización de semejante manera de actuar en el pasado de la comunidad suaba es su or gullo y, además, algo que les preserva del hundimiento. "Estamos ogullosos de nuestra comunidad. Nuestras habilidades nos preservan del hundimiento". Después de pasar revista también al pasado de la madre y percibir la ruptura que se ha producido entre ella y el suje to del recuerdo, suena el despertador a las cinco y media del domingo.

Si hubiese que buscar un hilo conductor que proporciona estructura unitaria a la obra y que la convierte en un texto literario conseguido, habría que encontrarlo en el género tradicional de la forma de narrar conocida en la tradición alemana ya desde el siglo XIX como Rahmenerzählung, a la que como muy bien puede entenderse se le han añadido nuevos elementos. Uno de los añadidos fundamentales es, sin embargo, la idea de la normatividad y su ruptura, que constituye el desencadenante con textual de la unidad del conjunto. Es la norma de un grupo social por la que es capaz de sacrificar sus vidas como individuos y negar por tanto en la vida del grupo la presencia del otro o de lo otro, en definitiva, de lo nuevo y distinto. En ella no se impide que la normalidad continúe a pesar de la violación, el incesto y otros comportamientos sobre los que no hay razón para estar or gullosos. La norma se ha convertido incluso, como titula la autora en uno de sus ensayos, en una realidad fija no libre de crítica y necesitada de cambio (Müller 1995: 90).

El yo narrador, en definitiva, se aparta, no encuentra otra solución que la de escapar y se exilia de un mundo que no acepta.

\section{CONTINUIDAD EN LA OBRA POSTERIOR A NIEDERUNGEN}

Toda la obra posterior de Herta Müller va a consistir en una continuación literariamente más conseguida y, a medida que pasa el tiempo, más depurada de lo que había comenzado en Niederungen. A ello hay que añadir además la impronta que van dejando las experiencias personales, caracterizadas por su vida en Rumanía, y las huellas profundas que en ella fueron fijando la emigración a Alemania y las nuevas vivencias.

Efectivamente, aún en Rumanía publica su segunda obra, Drückender Tango (Tango agobiante), de la que puede bien decirse que sigue la técnica y, a través de ella, el manejo de los mismos contenidos que Niederungen. El texto se publica dos años más tarde, todavía en Bucarest, y estructuralmente sigue la pauta marcada en el texto anterior como una colección de narraciones. Las primeras obras escritas en Alemania, después de la cesura que supuso la emigración a Berlín, son una conti nuación igualmente de la temática y la técnica utilizada con anterioridad. En Der Mensch ist ein groâer Fasan auf der Welt $(1986)^{4}$ describe las dificultades que trae

${ }^{4}$ Fue traducida en 1992 y publicada en la editorial Siruela con el título de El hombre es un gran faisán. 
consigo pretender una identidad propia frente a la arrogancia de la alemanidad, el fascismo y el socialismo. En Barfüâiger Februar (1987) (Febrero descalzo) introduce el tema de la memoria histórica. Es el recuerdo de la opresión del régimen de Ceaucescu y la aniquilación de los judíos alemanes rumanos con ocasión de un acontecimiento que afectó su vida personal, como fue la muerta violenta del poeta amigo Rolf Bossert. Algo similar ocurre con los textos escritos en los años noventa. La situación de la oposición en Rumanía, el final del dictador y de su sistema es el tema de Der Fuchs war damals schon der Jäger (1992) $)^{5}$. Con "Herztier" (1994) ${ }^{6}$ y Heute wär ich mir lieber nicht begegnet (1997) describe una sociedad en la que incluso lo más íntimo se encuentra envenenado por el recelo y la traición. El punto de vista concreto surge a partir de una experiencia dolorosa de la vida personal.

En los años de la primera decena del siglo XXI, la continuidad temática y estructural sigue el camino iniciado, si bien es cierto que es novedad llamativa la consi deración de la lengua además de como medio de opresión también como medio de oposición. Es lo que ocurre en la colección de ensayos Der König verneigt sich und tötet (2003) (El rey se inclina y mata), o en los poemas que reúne en Die Herren mit den Mokkatassen (2005) (Los señores con las tazas de moca) que son collages y recortes de periódicos.

\section{ATEMSCHAUKEL}

Pero sin lugar a duda, la gran obra con que se ha mostrado el desarrollo de sus capacidades como escritora ha sido Atemschaukel (2009). Podría pensarse e incluso afirmarse como ha hecho algún crítico que se trata de más de lo mismo. Pero no es así. Las novedades son evidentes. De entrada, llama la atención la historia de la producción del texto, que se proyectó para ser escrito junto con el autor rumano y buen amigo Oskar Pastior, un proyecto que tuvo que interrumpirse debido a su inesperada muerte. Él había proporcionado el material directo de las experiencias vividas como prisionero durante cinco años en la Unión Soviética. Por otro lado, en el epílogo se rinde información sobre el hecho de que la autora ya desde niña había oído hablar en la familia de las experiencias de los prisioneros, algo que en realidad ella entonces no entendía. Hasta más tarde no advirtió que además era algo relacionado con la cuestión del pasado fascista de Rumanía convertido en tabú entre la población. Ya en 2001 se había sentido atraída por el tema y pensó convertirlo en texto literario (Müller 2009: 298-299).

Los antecedentes históricos están presentes en el texto aunque no sea de una manera directa: la penetración del ejército soviético en Rumanía y la ejecución del dictador Antonescu; la sorpresa que significó la declaración de guerra a la Alemania nazi de la que hasta entonces Rumanía había sido aliada, y la exigencia del general Vinogradov, en nombre de Stalin, de la colaboración en la reconstrucción de la des-

\footnotetext{
5 Publicada también por Siruela en 1996 con el título de La piel del zorro.

${ }^{6}$ La bestia del corazón es el título con que se publicó esta obra en español en el año 1999.
} 
truida Unión Soviética de todos los alemanes rumanos, hombres y mujeres de entre 17 y 45 años que vivían en el país. El tema exterior fundamental del texto son las deportaciones del contingente humano tras la segunda guerra mundial. A lo largo de sesenta y cuatro partes se pasa revista al campo de concentración en que viven los internados como un lugar de dolor y de soledad, como el infierno de humanos en el que se desarrolla la vida de todos los días. Pero la obra no puede ser considerada un texto documental en el que se reproducen las informaciones del amigo y de los supervivientes que han vuelto al pueblo en que vive la propia autora. Es un texto ficticio logrado a partir, sobre todo, de las anotaciones tomadas del informe de Leopold Aubert, deportado con diecisiete años de Hermannstadt al campo de trabajo ucraniano de Nowo-Gorlowka. De esta manera el tema es algo que va más allá de la his toria que puso a su disposición Oskar Pastior. La ficción hace que se convierta en el símbolo del tratamiento injusto de millones de personas, de la violencia de la tiranía y de las víctimas causadas. Lo que llama la atención es que ya no se trata sólo de la historia reciente de Alemania, habitual en la literatura alemana, sino sobre todo de la Unión Soviética, y no cabe duda que también de Rumanía. Ciertamente se presenta un campo de concentración, pero de una manera muy diferente a como lo hizo Peter Weiss en su drama Die Ermittlung ${ }^{7}$, quien intentó documentalmente la reproducción de Auschwitz-Birkenau. Weiss tuvo que seleccionar, como no podía ser de otra manera, los acontecimientos del campo para hacer de su historia también una obra de literatura dramática. Herta Müller , que tiene también que seleccionar todo lo que conoce, da un paso más al hacer de la ficcionalización el objetivo fundamental, introduciendo otros elementos que ni siquiera proceden del lugar histórico, como la experiencia y postura personal ante los acontecimientos narrados y elementos de la propia vida. Es algo que sí se corresponde con lo que ha sido toda su actividad literaria anterior. De este modo se convierte en observadora omnisciente de los elementos del decurso de la obra. La ficción resulta ser, como ella misma ha manifestado, una autoficción. La autora real forma parte de ese pasado del que desaparece la identificación del aquí y el ahora a pesar de que se presente la historia del trabajo forzado en fábricas y la humillación de los trabajadores en ciudades de la estepa soviética, de las que a veces no conocen ni siquiera el nombre, como tampoco saben por qué se les ha condenado. Todo ello ha dejado en el protagonista una huella tan profunda que cuando vuelve a casa no es siquiera capaz de contar las experiencias que ha tenido. Es, por un lado, el reflejo de que durante el tiempo en que el protagonista ha estado internado, se ha producido en él un proceso que ha pasado por el deseo de volver a casa, pero que al estar en ella de vuelta, la fijación de la costumbre de un mundo completamente diferente no ha podido desaparecer de su conciencia y además domina su vida cotidiana. Ni siquiera siente la alegría que suele producir el hecho de volver. Por otro lado, en la mente del protagonista Leopold Aubert se ha perpetuado el tabú que antes era el modo de comportamiento de los habitantes del pueblo, lo que ha traído como consecuencia en él una forma de

\footnotetext{
${ }^{7}$ El título de la traducción al español de la obra de Weiss publicada en Círculo de Lectores en 1972 fue La indagación.
} 
actuar en su vida, cuya manera más genuina es manifestarse en el silencio. En tercer lugar, se produce la contradicción de no desear ya sentirse satisfactoriamente en el lugar de procedencia, en una sociedad que entiende como colaboradora de la Alemania nazi y que además es ahora hermana del gran sistema socialista igualmente totalitario:

Siete años después de la vuelta a casa estuve sin sentir añoranza [...]. Hay palabras que hacen conmigo lo que quieren. Son algo completamente distinto a mí... Añoranza. Como si la necesitase. Hay palabras que me tienen como objetivo, como si sólo estuviesen hechas para mi vuelta al campo de concentración, sólo con la excepción de la misma palabra VUELTA. Esta palabra sigue siendo absurda si es que para mí existe la vuelta. Absurda es también la palabra RECUERDO. Tampoco la palabra DETERIORO puede utilizarse para la vuelta. Tampoco la palabra EXPERIENCIA. (Müller 2009: 232-233)

Es una muestra de la habilidad literaria que se manifiesta en la expresión de la experiencia. El hambre que los internados padecen en el campo se convierte en un objeto, tal y como se lee en el capítulo "Vom Hungerengel" ("El ángel del hambre"):

El hambre es un objeto.

El ángel ha penetrado en el cerebro.

El ángel del hambre no piensa. Piensa de la manera adecuada.

No falla.

Conoce mis límites y sabe cuál es su

Dirección.

Conoce mi procedencia y conoce cuál es su

Efectividad.

Lo ha sabido antes de dar conmigo

Y conoce mi futuro

El ángel del hambre va con los ojos abiertos unilateralmente.

Se tambalea produciendo círculos estrechos y se balancea

En el columpio de la respiración...

Dice que vuelve, pero se queda allí donde está...

Una palada es igual a un gramo.

El hambre es un objeto. (Müller 2009: 143-144)

El ángel del hambre, por otro lado, sólo puede imaginarse como un espíritu que se adueña del hambriento y que se convierte en arma para poder luchar contra el hambre misma, pero se sueña con él, se convierte incluso en tema de chistes; se come un pequeño sueño, lo que es mejor que comer arena o excrementos, llega a decir una vez Leo. Las medidas no son en metros, sino que el lago, el ancho, el alto, el color de los objetos de dimensiones y peculiaridades concretas se miden según los parámetros del hambre. Llegado un momento en el que los internados reciben un pequeño salario y pueden con ello comprarse alimentos, es para Leo ya tarde pues el ángel del hambre le ha estrangulado con anterioridad. El significado metafórico es evidente, no sólo no podrá comer, sino tampoco vincularse a nadie y si llega a casarse es ni más ni menos que con el solo objetivo de adaptarse a las normas. De 
la individualidad no le queda más que el mundo interior , será a fin de cuentas lo único que va a permanecer siempre siendo propiedad suya. La vuelta a casa no significa otra cosa más que el conjunto de la autoenajenación y el sentimiento de la falta de una patria a la que siente que pertenece y que entiende como daños irreparables. Después del sufrimiento experimentado en el campo de trabajo no le queda prácticamente nada, si bien ha vuelto a la normalidad a la que podría haberse adaptado a la perfección sin esas experiencias. La expresión literaria de todo ello se manifiesta en un procedimiento de cosificación que llega de manera muy especial a expresarse en las propias palabras que se utilizan en la fábula:

Desde mi vuelta a casa ya no es mi riqueza AQUÍ ESTOY, pero tampoco AQUÍ ESTUVE. Ya no es riqueza mía DE AQUÍ YA NO ME MARCHO. Una y otra vez el campo de concentración se extiende desde la zona izquierda de la sien hasta la zona derecha. Así que no me queda más remedio que hablar de todo mi cerebro como si fuera toda una región. Uno no puede protegerse ni estando en silencio ni hablando. Se exagera tanto con lo uno como con lo otro. Pero ni en lo uno ni en lo otro existe AQUí ESTUVE YO. (Müller 2009: 295)

\section{EL EXILIO. EL RECUERDO. LA MEMORIA}

Herta Müller consigue simultanear el recuerdo de la realidad histórica de un pasado sobre el que todavía ni se ha reflexionado, ni mucho menos ha sido supera do, con la simbolización de un pasado personal ligado al grupo social de la comunidad rumano-alemana. Sea como fuere, Atemschaukel es una obra escrita con el objetivo de luchar contra el olvido, y aunque los hechos de la historia trasmitidos por Oskar Pastior sean alterados dentro del marco de lo literario, la base sobre la que están literaturizados es una base histórica. Por esta razón el texto puede muy bien ser considerado una obra escrita a favor del mantenimiento de la memoria histórica rumano-alemana. Es un pasado similar al de Alemania en el punto de partida. Ambos se fundamentan en los efectos causados por el Nacionalsocialismo. En Atemschaukel se trata de la historia de los rumano-alemanes que han padecido el sufrimiento y el dolor causado ciertamente de una manera directa por el terror del estalinismo, pero que al final es una historia entendida como consecuencia del Nacionalsocialismo. Es cierto que es una cuestión que en Rumanía todavía incluso hoy día no se ha tratado, mientras que en Alemania tanto la literatura como la intelectualidad comenzaron a ocuparse ya seriamente de ello en los años sesenta, a reflexionar sobre el pasado a fin de poder de esta manera superarlo. Con todo, la autora sabe que el punto de partida es distinto al de sus colegas alemanes que se ocupan de una cuestión semejante.

Los temas de los textos de Herta Müller han girado siempre en torno al exilio en el recuerdo, bien de su niñez en el Banat, bien del recuerdo de la situación opresiva de un sistema político totalitario, bien del trabajo duro a que estaban sometidos sus padres dentro de una agricultura estatalizada, bien finalmente del recuerdo de unos acontecimientos históricos protagonizados por rumano-alemanes después de la 
segunda guerra mundial en Ucrania. La literarización que de ello se realiza tiene lugar a través del filtro personal de la autora, que conoce los hechos por la experiencia personal o a través de las informaciones que recibe de otros. Nunca describe los hechos ocurridos de una manera directa, el material es siempre sometido a un proceso.

Pero el recuerdo a través del filtro de otra persona se convierte con Atemschaukel en el recuerdo ya no sólo de la experiencia de otra persona, sino en el recuerdo de la historia reciente de Rumanía, en una literarización de la memoria histórica que ya no es sólo la de un país sino que lo es de la historia reciente de toda Europa. No es la experiencia de la memoria histórica de la sociedad alemana que comenzó mucho antes a superar un pasado que durante tiempo había sido reprimido. Alemania tuvo la oportunidad de realizarlo por la sencilla razón de que el sistema liberal democrático que se instauró en el país pudo permitirlo. Las circunstancias en el país de origen de Herta Müller han sido completamente distintas. Con la continuación de un sistema dictatorial no era posible que a la sociedad rumana le estuviera permitido comenzar a cuestionarse lo que había ocurrido durante la segunda guerra mun dial, ni mucho menos a cuestionar la actitud de, al menos, parte de la misma frente a sistemas como el nacionalsocialismo o el socialismo dirigido inicialmente desde fuera. Herta Müller sí puede llevarlo a cabo aunque fuera veinte años después de la caída del muro de Berlín.

Ciertamente Atemschaukel puede dar la impresión de que la interioridad de la autora domina tan profundamente el decurso narrativo que los hechos históricos son un componente meramente secundario del texto. Es pura especulación preguntarse cómo habría sido el resultado si quien inicialmente estaba previsto como coautor no hubiese muerto. Sea como fuere, el resultado es la presentación de una experiencia vivida por otros muchos además de por el protagonista ficticio y , de esta manera, generalizable a otros no presentes en la obra. En consecuencia puede muy bien aceptarse que con la obra la autora ha tratado de recuperar y actualizar la memoria histórica.

\section{EMIGRACIÓN Y PERTENENCIA A UN PAÍS}

Es cierto que puede afirmarse que la autora es en sí una emigrante en Alemania, sin embargo esta cuestión no es fácil de resolver. Igualmente se infiere que la escritora está ligada a un mundo muy específico. De entrada se observa que no es el ambiente alemán occidental. Tal vez alguien pueda afirmar que la postura de Herta Müller ha cambiado con el paso del tiempo. Pero si uno se atiene a sus propias manifestaciones, todo ello puede de alguna manera aclararse.

En Reisende auf einem Bein, escrita poco tiempo después de llegar a Alemania, por boca de la protagonista Irene, hace ver las dificultades y la extrañeza que han surgido en su nuevo lugar de vida: "Viajeros, pensó Irene, con la mirada estimulada por las ciudades que duermen. En deseos que no son ya valederos. [... ] Viajeros sobre una pierna y sobre la otra pierna perdida. Los viajeros llegan demasiado tarde" (Müller 1989: 92). 
La protagonista de Reisende auf einem Bein se manifiesta como exiliada en un país que le resulta extraño y como una viajera que reflexiona sobre viajeros que se encuentran en situación semejante a la suya. Su sentimiento la lleva a sentirse incluso una marginada en un mundo que no es el propio.

En 1991 en una entrevista con Der Spiegel manifestó:

[...] también yo soy una extranjera, sólo que con la pequeña diferencia que el alemán es mi lengua madre, lo que al final no dice mucho. Quien como yo procede de Rumanía o de una sociedad diferente, lo primero que observa es qué pequeña es la identidad de la lengua. Todo lo que ocurre aquí en la República Federal, me resulta igual de extraño que a quien procede de Turquía o del tercer mundo. (Doerry y Hage 1992: 264)

Pero es que doce años más tarde de esta manifestación, ya en 2003, sigue sin tiéndose en situación similar, de manera que retomando las experiencias de la Irene de Reisende auf einem Bein (Viajeros de una sola pierna) el lector observa que se corresponden a las de la propia autora. Así lo manifiesta ella misma en el ensayo "Der fremde Blick oder das Leben ist ein Furz in der Laterne", incluido en Der König verneigt sich und tötet, donde cuestiona su propio escribir y sus condiciones históricas. Entiende que la lengua es fundamental como instrumento de opresión y de dominio, pero al mismo tiempo como medio de rebelión contra el poder totalitario. A partir de esa situación, el escritor se sitúa en un lugar determinado que le hace ver las cosas desde la visión de un extraño, y como un extraño utiliza la lengua. El resultado es que a la situación de mar ginado se añade la situación de oprimido, y la lengua del escritor reacciona en consecuencia, es decir , como el resultado de una forma de escribir propia de alguien que no pertenece al mundo en que vive y cuya identidad además no está garantizada.

Lo que el autor expresa no es lo extraño propiamente dicho, sino lo que se entiende por extraño, que no es lo contrario de lo conocido sino lo contrario de lo próximo, de lo habitual: "Extraño para mí no es lo contrario de conocido sino lo contrario de habitual" (Müller 2003: 136).

Pero ocurre que la forma extraña de observar las cosas se realiza mediante la uti lización de una lengua determinada que es el alemán, lo que lleva a preguntarse por qué hasta ahora Herta Müller se ha considerado una persona extraña si habla la misma lengua que la del país que la ha acogido y en el que vive.

Una conferencia a bachilleres pronunciada por ella en 2001 lleva el título de "Patria es lo que se habla". El título ya expresa una referencia que refleja la actitud personal frente a los escritores alemanes. En este trabajo la autora se opone a quienes entienden que la lengua es país, pueblo, cuna, origen. Para ella es algo muy distinto (Müller 2001: 24 y ss.). Para expresar la diferencia acude a la expresión de Semprún de que "país" es lo que se habla; lo que significa que alguien sólo puede sentirse bien en un sitio si allí se puede decir lo que se quiere. El sentimiento de patria le fue arrebatado por el hecho de que tuvo que sufrir una dictadura que le impidió decir libremente en su lengua lo que pensaba.

En este sentido la experiencia que tuvo en un viaje a Roma es muy significativa. En esta ciudad fue considerada alemana y fue allí precisamente donde pudo darse 
cuenta de lo poco que significa esta denominación y qué poco dice sobre una per sona (Doerry y Hage 1992: 264). Ahora bien, ello en principio no debería impedir adquirir un sentimiento de patria en otra parte, como podía ser en Alemania. Pero previamente al planteamiento de la cuestión ya contesta ella cuando dice que una vez que a uno se le ha arrebatado el sentimiento de patria, ya no puede adquirirlo en otra parte, pues se le ha impedido pensar y además se le ha impedido también des arrollar las capacidades individuales (Müller 2001: 28).

En 1997, unos años antes de la publicación de "Heimat ist das, was gesprochen Wird", en una entrevista con Wolfgang Müller en el Dickinson College de Carlisle añade, además, la importancia que tiene el componente que constituye el mundo en que se encuentra.

Pero si el entorno ha sido, como es mi caso, primero esa dictadura, después ade más esta minoría con la que entré en conflicto por los libros, ocurre que no enca ja. Cuando el entorno no me acepta, puedo vivir en él cien años y no levantar jamás de él las plantas de los pies, pero nunca estaré en una patria así. (Müller 1997: 468-469) ${ }^{8}$

Y en 2009, lo que parece definitivo, manifiesta:

"Mis compatriotas me han excluido, ya me excomulgaron después de la obra Niederungen en los primeros años ochenta, luego vino todo el ajetreo con el servicio secreto y la dictadura", dijo Müller en conversación con el Süddeutsche Zeitung. "Luego llegué aquí, y naturalmente no he llegado a una patria. Vivo aquí, pero aquí no me siento en casa porque no soy de aquí, y allí no me sentía en mi casa porque no era de allí”. (Die Presse 2009) ${ }^{9}$

Y a continuación expresa algo que es muy significativo y que ayuda a explicar la situación especial de exilio que vive desde que era niña en Rumanía: “"La lengua alemana está siempre presente'. Dice no haber aprendido rumano hasta los quince años. 'De manera que no sé lo que soy . Algo de los dos y nada de ninguno"' ( Die Presse 2009).

Este, puede concluirse, es el sentimiento que refleja la situación personal de la escritora. No es otro que el de una exiliada que se siente extranjera en el país de acogida pero con el agravante de que no es que haya perdido la patria anterior, sino que también allí se sintió una exiliada.

\footnotetext{
${ }^{8}$ La entrevista tuvo lugar el 5 de julio de 1996 en el Dickinson College, donde vivía como "W riter in Residence" durante el semestre de primavera del año 1996.

9 El periódico digital Die Presse recoge los testimonios publicados previamente en Süddeutsche Zeitung.
} 


\section{BIBLIOGRAFÍA}

AUFFERMANN, Verena; KÜBLER, Gunhild; MÄRZ, Ursula; \& SCHMITTER, Elke (2009): Leidenschaften. 99 Autorinnen der Weltliteratur. Bielefeld: Bertelsmann Verlag.

CARTARESCU, Mircea (2009): „Das Schwert im Innern“ [on-line]. Frankfurter Rundschau. Feulleiton, 12/10/2009. En: www.fr-online.de.

DER TAGESSPIEGEL (2009): „Thomas Brussig über Herta Müller“ [on-line]. Der Tagesspiegel, 08/10/2009. En: www.spiegel.de.

DIE PRESSE (2009): „Herta Müller sieht sich als Heimatlose“ [on-line]. Die Presse, 09/10/2009, 12:46. En: DiePresse.com.

DOERRY, Martin; \& HAGE, Volker (1992): „So eisig, kalt und widerlich“. Der Spiegel, 46.

FRANKFURTER ALLGEMEINE ZEITUNG (2009): „Banater Schwäbin erhält Literatur Nobelpreis“" [on-line]. Frankfurter Allgemeine Zeitung, 10/10/2009. En: www.faz.net.

FRANKFURTER RUNDSCHAU (2009): „Kein Wort über Herta Müller. Reich Ranicki verhängt sich Maulkork“ [on-line]. Frankfurter Rundschau, 09/10/2009. En: www.fr-online.de/kultur.

FRANKFURTER RUNDSCHAU. FEUILLETON (2009a): „Bundespräsident würdigt Herta Müller“ [on-line]. Frankfurter Rundschau. Feuilleton, 12/10/2009. En: www .fr-online.de.

- (2009b): „Berlin würdigt Herta Müller. Gastprofessorin“, [on-line]. Frankfurter Rundschau. Feuilleton, 12/10/2009. En: www.fr-online.de.

KATHOLISCHE NACHRICHTEN DOM RADIO (2009): „Erzbischof Zollitsch und Bischof Huber würdigen Herta Müller" [on-line]. Katholische Nachrichten Dom Radio, 10/10/2009. En: http://www.domradio.de/.

KÖHNEN, Ralph (2002): ,T error und Spiel. Der autofiktionale Impuls in frühen texten Herta Müllers“. Herta Müller, Text+Kritik. Zeitschrift für Literatur, Cuaderno 155, Julio 2002.

MÜLLER, Herta (1984): Niederungen. Berlin: Rotbuch-Verlag.

- (1989): Reisende auf einem Bein. Berlin: Rotbuch-Verlag.

- (1995): Hunger und Seide. Berlin: Reineck.

- (2001): „Heimat ist das, was gesprochen wird“. Blieskastel: Gollenstein Verlag.

- (2002): "Wenn schweigen, werden wir unangenehm - wenn wir schweigen, werden wir lächerlich“. Herta Müller, Text+Kritik. Zeitschrift für Literatur, Cuaderno 155, Julio 2002.

- (2003): „Der fremde Blick oder Das Leben ist ein Furz in der Laterne“, en Der König verneigt sich und tötet. München: Carl Hanser Verlag.

- (2009): Atemschaukel. Roman. München: Kart Hanser Verlag.

MÜLLER, Wolfgang (1997): ,,,poesie ist ja nichts angenehmes’ - gespräch mit Herta Müller". Monatshefte, 89, 4.

REGIERUNGONLINE (2009): www.bundesregierung.de, 08/10/2009.

SPIEGEL ONLINE (2009): „Nobelpreis für das Drama ihres Lebens“ [on-line].Spiegel online, 20/10/2009. En: www.spiegelonline.de.

TAGESSCHAU (2009): 15:00 Uhr, 08/10/2009.

WEISS, Peter (1972): La indagación. Barcelona: Círculo de lectores.

WELT ONLINE (2009): „Reaktion auf Nobelpreis. Rumänien tut sich schwer“ [on-line].

Welt online, 09/10/2009. En: www.welt.de. 